\title{
Carolina del Norte and the New South: Social Work Practice With New Latino Immigrant Communities
}

\author{
Lisa de Saxe Zerden \\ Arianna Taboada \\ Quentin Joshua Hinson
}

\begin{abstract}
Over the past decade, the Latino population in North Carolina has increased $111 \%$. More than half of North Carolina Latinos are foreign-born and most face issues related to immigration, acculturation, and often, discrimination. This article provides a brief overview of the historical context in which social workers engaged with immigrant communities and argues that the profession brings strengths and unique skills to address North Carolina's Latino immigrant population, historically, and within the current context. Key social demographics of Latino populations, sociopolitical realities, and theoretical and methodological issues related to the complex needs of this diverse population group are addressed. Two examples of Latino vulnerability in North Carolina, HIV/AIDS and discriminatory local immigration enforcement practices, are discussed to further highlight the unique strengths and challenges social workers in North Carolina and the New South face when working with Latino immigrants.
\end{abstract}

Keywords: Latino immigrants, immigration policy, acculturation, Latino HIV/AIDS risks

The Latino population is the country's largest growing minority group and is projected to comprise 45\% of the U.S. population by 2030 (U.S. Census Bureau, 2010). Currently, Latinos/Latinas represent more than 50.5 million individuals, or $16.3 \%$ of the total population and accounted for $56 \%$ of the U.S. population growth between 2000 and 2010 (U.S. Census Bureau, 2010). During that decade, seven southeast states had Latino populations that more than doubled, including North Carolina (Pew Hispanic Center, 2011). The Latinization of the "New South" as described by Furuseth and Smith (2006) has contributed to

...transformative forces reshaping the character and dynamics of the region in our area. The immigration of both native and foreign born [Latinos] and their role in the emerging Nuevo South cannot be understood fully without interacting it with changes that are transforming the region's economy and culture through...restructuring and globalization. (p. 15)

It is important to recognize that hundreds of thousands of Latinos have moved to North Carolina and other southern U.S. states as a result of increasing labor demands, growth in the southern regions, and a cheaper cost of living (Gill, 2012). Due in part to these as well as other factors, North Carolina experienced a rapid demographic shift from 1990 to 2000, with the fastest growing Latino population in the nation (Martinez \& Bazan, 2004). Over the past decade, the Latino population in the state has continued to grow, increasing from 378,963 in 2000 to 800,120 in 2010 —a dramatic increase of 111\%

Lisa de Saxe Zerden, MSW, Ph.D., is a Clinical Assistant Professor in the School of Social Work at the University of North Carolina at Chapel Hill; Arianna Taboada, MSW, MSPH, is Project Manager at the UCLA Art \& Global Health Center, and Quentin Joshua Hinson, MSW, LCSW, LCAS, is a Clinical Instructor in the School of Social Work at the University of North Carolina at Chapel Hill.

Copyright (C) 2013 Advances in Social Work Vol. 14 No. 1 (Spring 2013), 260-275 
(Pew Hispanic Center, 2011). With more than 800,000 Latinos living in North Carolina, this group accounts for approximately $8 \%$ of the state's current population (U.S. Census Bureau, 2010). More than half of North Carolina Latinos are foreign-born (Zota, 2008), and 35\% report limited or no English proficiency (U.S. Census Bureau, 2005-2009). Most face issues related to immigration and acculturation as well as discrimination in their new communities, and, one third are estimated to be undocumented (Popke, 2011), adding an additional element of social vulnerability.

Many recent Latino immigrants have found employment in North Carolina's agricultural sector, primarily as laborers on turkey and hog farms, or with landscaping and horticulture businesses; in the construction and construction-related trades, such as painting and carpet installation; in housekeeping services, and other service-sector jobs (Gill, 2012; Popke, 2011). The increase in labor-driven transnational migration is often attributed to the economic restructuring of the region that is tied to neoliberal policies (as exemplified by the North American Free Trade Agreement [NAFTA] of 1994), coupled with the state's history of weak unions and racially segregated labor (Popke, 2011). Despite the active recruitment of Latino/Latina workers by select industries, the local reception of the influx of Latinos has been fraught with anxiety, fear, and larger sociopolitical challenges. These responses differ in degree and severity, often in relation to patterns of migration and reception. The changing landscape of rural communities in North Carolina has been dramatic. Major urban centers in Durham, Mecklenburg, and Wake counties received large numbers of Latino immigrants between the years 20002010 (Nguyen \& Gill, 2010). However, rural counties within the state, such as Cabarrus and Duplin, experienced rapid demographic shifts, with the percentage of Latino residents increasing by $1000 \%$ while other racial/ethnic groups remained the same or decreased (Nguyen \& Gill, 2010; Popke, 2011). Social backlash became prominent as Latino migrants intersected the lives of native-born Carolinians. Given the complex economic and labor-related drivers of demographic changes, Latinos' labor has been welcomed, yet the presence of a permanent Latino community has not received the same reception (Gill, 2012; Johnson-Webb, 2003). In both rural and urban settings, as the landscape of the state has begun to include brown faces, tiendas, taco trucks, and Spanish-language signs and advertising, the conservative public reaction to the demographic shift has grown louder. Paralleling this conservative backlash, academic and activist work focused on diversity has grown stronger (Cravey \& Valdivia, 2011; Cuadros, 2011; Deguzman, 2011; Palis, Reilly, \& Valdivia, 2011). This is a trend that is echoed throughout historical accounts of communities receiving newcomers (Abel, 2004; Chavez, 2004; Molina, 2006a, 2006b; Portes \& Rumbaut, 2006).

Among states with a growing Latino/Latina population, North Carolina has a somewhat unique history. Although the state had been receiving Mexican workers in small numbers since the 1940s (i.e., when the Bracero Program imported temporary Mexican agricultural workers to the United States) North Carolina did not begin to actively address the social, economic, and health disparities of Latinos until the 1990s when a permanent Latino community was established (Martinez \& Bazan, 2004). The response of social services has been slow and hindered by many logistical and political challenges. One such challenge is the lack of professionals trained to address the unique 
needs of this population. However, given the social work profession's roots in social justice work, multisystemic orientation (i.e., micro, mezzo and macro) and person-inenvironment perspective, social workers are particularly well positioned to address the Latino community's needs through direct service, community practice, and political advocacy (Garcia, 2009).

This article offers an overview of social workers engaging with immigrant communities and argues that the profession brings strengths and unique skills to address North Carolina's Latino immigrant population, historically, and within the current context. However, equally important are the limitations within social work education to educate professionals on the nuances of migration and acculturation theory and its application in practice. Therefore, this article highlights key social demographics of Latino populations, as well as theoretical and methodological issues related to the complex needs of this diverse population group. A review of these concepts will help prepare social work practitioners for a more comprehensive and culturally informed understanding of Latino immigrant communities, and, in turn, promote development of culturally relevant interventions that consider sociopolitical realities. Two examples of Latino vulnerability in North Carolina-HIV/AIDS and discriminatory local immigration enforcement practices-are discussed to further highlight the unique strengths and challenges social workers in North Carolina and the New South face when working with Latino immigrants.

\section{Latino Social, Health, and Economic Vulnerabilities}

North Carolina's Latino immigrants face complex and often multiple layers of social, health, and economic challenges, depending on various facets of human and social capital, including level of education, English language proficiency, documentation status, social support, level of acculturation, and ethnic identity (Delgado, 2012). In particular, immigrant Latinos in North Carolina face major challenges to maintaining their health because of structural barriers such as lack of access to care, lack of linguistically and culturally appropriate services, inadequate transportation, lack of employer-based insurance, and prominent racial/ethnic discrimination (Siman, 2009). Latinos represent the racial/ethnic group most likely to lack insurance in North Carolina, with an estimated $65 \%$ of adults and $30 \%$ of children uninsured. Additionally, $29 \%$ of Latino adults in North Carolina report that they were unable to see a physician when needed in the past 12 months due to cost (North Carolina Office of Minority Health \& Health Disparities and the State Center for Health Statistics, 2010). Perhaps most dramatically, Latinas in North Carolina have some of the highest rate of teen pregnancy in the country (Martinez \& Bazan, 2004).

Data from multiple sources indicate that nationally, Latinos suffer disproportionately from poverty and lack of access to health care (Delgado, 2007), and that undocumented immigrants are even more vulnerable given their exclusion in federal health coverage, including the recent passage of the Affordable Care Act (ACA) in 2010 (Galarneau, 2011). Under the ACA, undocumented immigrants are ineligible for Medicaid and will not be allowed to purchase private insurance through new insurance exchanges (Galarneau, 2011). 
According to the U.S. Census Bureau (2010), almost a quarter of U.S. Latinos live below the federal poverty line, and $40 \%$ of the population is younger than 21 years of age, with limited formal education (Warner et al., 2006). These social factors intertwine with and influence health and well-being, warranting social workers to examine not just individuals in their environment, but also, what kind of fit one's environment has on individuals. This is known as the person-environment fit model and it has been used to explain some of the diversity in adjustment among Latinos and their movement patterns (Roosa et al., 2009). How well immigrants fit in their communities looks drastically different depending on the resources, support, neighborhood composition, and desires of individuals (Garcia, 2009). Critical consideration is needed of an array of factors influencing Latino well-being which includes socioeconomic status; cultural attributes; neighborhood composition; social reception; language proficiency; legal status; access to health insurance; and access to appropriate preventative care, treatment, and service provision (Centers for Disease Control and Prevention [CDC], 2012; Friedman, Curtis, Neaigus, Jose, \& Des Jarlis, 1999; Vega \& Amaro, 2002).

Within-group variation in health outcomes is often obscured because data on the U.S. Latino population is aggregated, perpetuating the false assumption that Latinos are a homogenous group. Many of the above characteristics do not account for the heterogeneity among this diverse group. Specifically, in North Carolina, two thirds of the Latino population identifies Mexico as their country-of-origin, followed in order by El Salvador, Honduras, Guatemala, and Costa Rica. These numbers include immigrants, naturalized citizens, and U.S. born citizens (Gill, 2012; U.S. Census Bureau, 2010). Further, most data on Latinos as a group fails to consider acculturation factors such as nativity, length of time in the United States, language spoken, developmental stage at age of migration, and other migration and immigration patterns that differ drastically within Latino ethnic groups (Zerden, Lopez, \& Lundgren, 2010).

The particular needs of Latinos and immigrant communities have prompted social workers to think critically about the ways in which research and intervention efforts capture the immigration, migration, and adaptation processes. The policies and politics tied to the Latino immigrant experience play a central role in the quality of services available in receiving communities. Culturally-informed practitioners have a professional and ethical obligation to understand the cultural, gender, social, health, and economic nuances Latino immigrant communities experience in light of their unique immigration circumstances and the ever-changing landscape of immigration policy (Chang-Muy \& Congress, 2009; DeRose, Escarce, \& Lurie, 2007).

\section{Overview of Social Work's Role in Working with Immigrants}

From the inception of social work, the profession has played a role in adapting to immigration and migration (Chang-Muy \& Congress, 2009). While a full history is beyond the purview of this article, the extent of racism and exclusion within early social work institutions such as settlement houses and charity organizations should not be negated. This declaration by a settlement house director, "You can Americanize the man from southeastern and southern Europe, but you can’t Americanize a Mexican” (as cited in Iglehart \& Becerra, 1995/2000, p. 5) exemplifies a dominant and professionally 
acceptable perspective at the turn of the nineteenth century. Despite a longstanding commitment to immigrant populations, the professionalization of social work and the creation of formal social service organizations rarely met the specific needs of immigrants (Iglehart \& Becerra, 1995/2000; Katz, 1996). Services were thought to be "culturally neutral" but often reflected the values and beliefs of dominant White culture (Bent-Goodley, 2005; Katz, 1996), and thus, excluded ethnic and linguistic minority groups from mainstream formal services. Therefore, ethnic service agencies took responsibility for providing the organizational structure and services to ethnic and linguistic minority groups (Iglehart \& Becerra, 1995/2000).

More recently, the social work profession has shown a renewed commitment to working with immigrant populations with respect and dignity. Most notably, the National Association of Social Workers (NASW) Code of Ethics frames standards for professional practice with immigrants in its sections on culturally competent practice (NASW, 2008). NASW recently added immigration status as applying to a category of people for whom social workers should oppose discrimination (NASW, 2012). Similarly, the Council on Social Work Education (CSWE) Educational Policy and Accreditation Standards speak to the importance of preparing culturally competent students for practice in global societies (Chang-Muy \& Congress, 2009; CSWE, 2012). These changes have been reflected at a curricular level as social work educators have endeavored to better prepare students to work with an increasing number of clients who are immigrants settling into new communities (Furman, Negi, \& Loya, 2010; Negi \& Furman, 2010). Recently, many schools of social work have developed concentrations and certificate programs related to immigration and transmigration. These programs are designed to better prepare future social workers for the critical analysis required to effectively work with diverse groups of immigrants and the myriad of social, economic, political, legal and psychological issues associated with immigration (Nash, Wong, \& Trilin, 2006).

Several of the theoretical perspectives foundational to social work are also beneficial to assessing immigrants, their families, and community systems: empowerment theory (Gutiérrez \& Lewis, 1999; Weil, Reisch, \& Ohmer, 2012), strengths-based perspective (Saleebey, 2002), bioecological systems perspective (Bronfenbrenner, 1979), and the risk and resiliency perspective (Fraser, 2004). To adequately account for the nuances that shape individual and community risk and resilience across social work settings, social work students and practitioners need to understand immigrant issues through the lenses of human rights and social justice, which are core principles of the profession (Congress, 2006; NASW, 2012; Weil et al., 2012). For those interested in working with Latino immigrant communities, this perspective includes understanding human rights issues in Latin America, as well as the concepts and theories relevant to serving a diverse population.

Although the literature on migration as a human right is well developed (Simmons, 1996; Tazreiter, 2006; Touzenis \& Cholewinski, 2009) and used in social work education, acculturation has been a debated concept in social and health sciences. The difficulty in teaching social workers about acculturation primarily stems from the fact that acculturation theory has been ambiguously defined and inconsistently used in social science research (Hunt, Schneider, \& Comer, 2004), despite being an important concept 
for social workers to understand in order to discern the structural forces that impact movement, migration, cultural values and health-seeking behaviors.

\section{Acculturation Theory}

The concept of acculturation has had a long history within social and behavioral sciences, especially among anthropologists and sociologists first documenting their encounters with indigenous populations (Cabassa, 2003; Hunt et al., 2004). Early conceptualizations viewed acculturation as a unidirectional process in which a cultural group moved from a tradition-oriented phase, through a transitional phase, to a final, acculturated endpoint (Cabassa, 2003; Chun, Organista, \& Marín, 2002; Hunt et al., 2004; Redfield, Linton, \& Herskovitz, 1936). A more contemporary perspective rejects this linear view of culture and opts for a multidimensional approach throughout the life course (Cabassa, 2003; Chun et al., 2002) that represents a dynamic, context-dependent construct wherein individuals move along a continuum (Yamada, Valle, Barrio, \& Jeste, 2006).

Acculturation as a continuum is a particularly important concept for Latino groups who represent diverse migration patterns and points of entry (Thomson \& HoffmanGoetz, 2009). Whether the acculturation process occurs on a voluntary basis or is forced (e.g., refugees or laborers immigrating out of necessity), such a process contributes to acculturative stress, that is, the collective confusion and anxiety, loss of identity, and feelings of alienation against the larger society (Portes \& Rumbaut, 2006; Smokowski \& Bacallao, 2011). However, using acculturation as a concept in assessing the social, health, and political outcomes of Latinos is a complex matter given the lack of standardized definition and measure, as well as the limitation that few assessments include specific health indicators (Wallace, Pomery, Latimer, Martinez, \& Salovey, 2012).

Measuring acculturation for Latinos and limitations. Although an array of acculturation measures have been designed to quantify the behaviors, values, and attitudes of the Latino population, a major criticism within acculturation literature is the "lack of clear definitions and insufficient conceptualization of acculturation, its central concepts remain implicit, poorly stated, simple, ambiguous, and inconsistent” (Hunt et al., 2004, p. 975; Wallace et al., 2012). Many studies have used acculturation theory to examine the relationship between acculturation and health outcomes among immigrant groups (Abraido-Lanza, Armbrister, Florez, \& Aguirre, 2006; Delgado, 2007; Zerden et al., 2010) without a more comprehensive analysis of the multiple systems at play (Hunt et al., 2004) or cultural attitudes, knowledge, and beliefs that influence healthcare utilization (Wallace et al., 2012). The majority of acculturation scales have been tested with nonprobability samples of predominantly Mexican American subgroups of Latinos who are often first-generation immigrants living in California or Texas (Yamada et al., 2006).

One of the biggest limitations of acculturation theory in health outcome research has been identified as the overreliance on individual and culture-driven models to understand health disparities. Zambrana and Carter-Pokras, (2010) state that this limitation "ignores the effect of residence in low-resource communities, low SEP (socioeconomic position), the social construction of marked cultural identities, and institutional patterns of unequal 
treatment, all of which contribute to health disparities” (p. 21). Expanding social and public health research to include social determinants of health, as well as institutional and structural barriers to care will improve the understanding of health disparities by acknowledging that these facets often impact the ways in which individuals experience acculturation, migration and movement in the first place.

\section{Case Examples: Health and Political Implications of HIV/AIDS and Local Immigration Enforcement}

To build on the articulation of demographic shifts of Latinos in the South as well as the ways in which theoretical constructs inform measurement and enumerate social, economic, and political conditions, the following section presents two case examples of vulnerabilities experienced by Latinas/Latinos in the southern United States. These case examples center on issues around (a) HIV/AIDS and (b) local immigration enforcement; our discussion focuses on how social work professionals are particularly equipped with the knowledge and skills to deal with these situations experienced by Latinos in North Carolina and other southern states.

\section{HIV/AIDS}

Although HIV/AIDS knows no geographic, economic, or racial/ethnic boundaries, minorities disproportionately bear the burden of disease. This disparity has remained true for HIV/AIDS rates in the South where half of new HIV diagnoses among Latinos occurred (CDC, 2012). From 2006 to 2009, 6 of the 10 states with the highest rates of HIV infection among Latinos were in the South (CDC, 2012). Nationally, Latinos accounted for $13.4 \%$ of the population yet $18 \%$ of new HIV diagnoses from 2005 to 2008 were among Latinos (CDC, 2012). The increasing population growth of Latinos in the South over the past decade and disparities in health outcomes warrant greater focus on HIV/AIDS prevention, treatment, and care needs of Latino communities.

As demographic and geographic shifts continue to shape the landscape of HIV/AIDS among Latinos is the United States, the person-in-environment perspective intrinsic to social work recognizes the multisystemic factors that perpetuate HIV/AIDS risks and the protective factors for which culturally appropriate interventions can be harnessed for Latinos in North Carolina specifically, and the Southeast generally. There is significant evidence that shows how social marginalization and isolation experienced by Latino immigrants can result in high-risk behavior associated with sexual practices and intravenous drug use (Castillo-Mancilla et al., 2012; Ojeda et al. 2012; Painter, 2008). Research has shown that health interventions that are adapted to a specific ethnic group's cultural and social context are more likely to increase effectiveness (Bernal, Bonilla, \& Bellido, 1995). Social workers are well positioned to consider multiple factors of discrimination that subgroups might experience, and, within this context, provide services and lead advocacy efforts. The profession's emphasis on cultural competency requires social workers to critically understand a context unique to Latinos versus other racial/ethnic subgroups. Culturally relevant and linguistically appropriate services are needed for counseling and testing services, educational materials, and prevention efforts. Simply asking specific questions regarding a client or community's legal, cultural, and 
linguistic context can dramatically improve the prevention or treatment approach and mitigate the potentially harmful effect of providing services based on assumptions or generalizations about an ethnic group (Tervalon \& Murray-Garcia, 1998). A strong understanding of acculturation can facilitate the provision of culturally and linguistically competent care.

Further, partnerships with community-based organizations serving the Latino community in the South are necessary to promote trusted and safe environments in which Latinos can seek social, psychological, and health support outside of the formal social service sector. The use of promotoras, or lay health workers, has a long history in both Latin American and U.S. Latino communities of effectively bridging the gap between the community and health services. Promotoras are noted not only for increasing knowledge and promoting community-level change, but can actually facilitate individual behavior change, use of preventive service, and access to health care services at a relatively low cost (Cohen, Meister, \& deZapien, 2004; Ingram, Gallegos, \& Elenes, 2005; Love, Gardner, \& Legion, 1997; Nemcek, \& Sabatier, 2003; Ramos, May, \& Ramos, 2001; Ro, Treadwell, \& Northridge, 2003).

Promotoras have been an effective community-centered intervention to reach vulnerable Latino groups affected by HIV/AIDS (Vega \& Cherfas, 2012). Identifying promotoras in North Carolina and other southern states is not only a valuable way for social workers to build community capacity through empowerment of community leaders but also to identify community needs and receive feedback about the cultural relevancy and feasibility of interventions within Latino communities (Vega \& Cherfas; 2012; Witmer, Seifer, Finocchio, Leslie, \& O’Neil,1995). Furthermore, and particularly important in the case of HIV among North Carolina Latino immigrants, promotoras can help promote critical points of access for prevention, treatment and social support (Aguilar-Gaxiola et al., 2002; Nemcek \& Sabatier, 2003).

\section{Local Immigration Enforcement - 287(g)}

Historically, public policies targeting immigrants have had a significant impact on Latino communities; such policies continue to be fraught with controversy (Abel, 2004; Hernández, 2008; Molina, 2006a, 2006b). With recent increases in the Latino immigrant population, North Carolina has been called "an important barometer of contemporary immigration debates for the nation and especially for the Southeast, which has become a new frontier for Latin American migration to the U.S.” (Gill, 2012, p. 6). North Carolina has joined several other states and local municipalities in adopting local- and state-level strategies, arguably to address the lack of comprehensive immigration reform at the national level (Idilbi, 2008).

Although neighboring southern states, including Alabama, Georgia, and South Carolina passed stringent immigration laws similar to Arizona's SB1070, several North Carolina counties and the City of Durham opted to participate in the 287(g) program sponsored by U.S. Immigration and Customs Enforcement (ICE), a division of the Department of Homeland Security (Gill, 2012). The 287(g) program gives local law enforcement the authority to assess for immigration status and start deportation 
proceedings for undocumented suspects who are detained, but have not yet been convicted of any crime (Gill, 2012). Although originally developed to promote safe and secure communities, the implementation of 287(g) in North Carolina has repeatedly been recognized as a primarily anti-immigration initiative that heavily intersects with racial/ethnic discrimination and racial/ethnic profiling under the guise of reducing crime (Gill, Nguyen, Parken, \& Weissman, 2009; Idilbi, 2008; Nguyen \& Gill, 2010; Weissman, 2009).

Despite a dearth of literature available on the impact of 287(g) in North Carolina specifically related to social work practice, evidence gathered by economists, lawyers, and policy makers has suggested that $287(\mathrm{~g})$ is detrimental to Latino immigrants' experience with harassment and isolation, trust in public safety, and ability to contribute to local economies, which have been strengthened by Latino small businesses and tax revenues (Gill et al., 2009; Idilbi, 2008; Nguyen \& Gill, 2010; Weissman, 2009). Further, policies like 287(g) are suspected to severely threaten the physical and mental health of immigrants targeted by the practices generated by such policies (Hacker, Chu, Arsenault, \& Marlin, 2012; McLeigh, 2010). When communities have enacted local enforcement of federal immigration policy, both documented and undocumented immigrants living in those communities have reported negative health effects such as heightened stress levels, fear of deportation, and emotional distress (Hacker et al., 2012). These increased stressors lead to negative effects in wellbeing at the individual, family, and community levels. Social work, as a field with a social justice perspective, should play a particularly critical role in both direct service and advocacy in response to 287(g).

However, the symptoms mentioned above also result in limited help-seeking for health and social services, which are the primary points of contact where social workers and other helping professions are most likely to have direct contact with the Latino population. Anecdotal evidence from the experiences of one of the authors, a bilingual clinical social worker in North Carolina's Triangle area from 2006 until 2010, during the enactment of 287(g) and the 2006 Technical Corrections Act (which required a valid Social Security number to qualify for a North Carolina driver's license), corroborate that the policies severely limited the organization's capacity to serve its target population. The social worker reported that once 287(g) was enacted, the agency's Latino clients reported increased fear and anxiety about leaving their homes and being targeted at license checkpoints. In addition, highly publicized cases that shed light on the racial profiling and victimization of Latino immigrants exacerbated clients' fears and increased their isolation by discouraging them from seeking social supports. Clinical manifestations of anxiety and depression were compounded by acculturation stress and became more difficult to treat with access to treatment in jeopardy.

\section{Conclusions: The Role of Social Workers in the New South}

The recent demographic shifts, burgeoning Latino communities, and accompanying vulnerabilities in North Carolina suggest that through direct service, community practice, and political advocacy, social workers have essential skills and professional responsibilities to address the needs of Latinos in the South. Examples of the intensifying HIV/AIDS epidemic and discriminatory immigration policies prone to the South are but 
two examples of the needs Latino immigrants and migrants will continue to face in the New South. Although geographic factors, including rural isolation, cultural conservatism, and increased poverty are more pervasive in the South, the necessity for social workers to address the particular nuances of new Latino immigrant communities has never been greater for the nation as a whole. However, identifying the skills and approaches that social workers bring and need to strengthen is critical.

The theoretical orientation of social work education and the profession's understanding of multisystemic social problems allow social workers to think critically about these issues, including HIV/AIDS prevention and treatment, and the impact of unjust and discriminatory immigration policies. In addition to providing culturally appropriate, trauma-informed direct services to address deleterious mental health effects of such policies, social workers can advocate for policy change at the local, state and federal levels. In addition, social workers are especially well equipped to involve Latinos in such advocacy efforts, thereby empowering Latinos to step out of the shadows and increase their sense of agency (Belkin-Martinez, 2010). These social work foundational skills must be examined within the historical context of the field and coupled with efforts in related fields such as sociology, public policy, public health, and law.

Historical perspectives from the field of social work trace a long history of work with immigrant populations, although noticeably void of some of the ethical principles of cultural competency and anti-discrimination that are now in place. Social work educators must work to actively infuse the curriculum with content that addresses these principles and frames practice with immigrant communities in a social justice and human rights context. Careful consideration of local and global policies and practices that operate in conjunction with one another to prevent or facilitate the human dignity of migrant populations is critically important, as is the understanding of nuances of language, culture, and acculturation. Careful consideration of systems in the country-of-origin, transit, and destination are other ways in which social workers serving Latino immigrant populations

must engage with these concepts as they are defined across the Americas, paying close attention to the ways in which the New South's challenges can be attributed to a truly global issue.

\section{References}

Abel, E. (2004). Only the best class of immigration: Public health policy toward Mexicans and Filipinos in Los Angeles, 1910-1940. American Journal of Public Health, 94(6), 932-939. doi:10.2105/AJPH.94.6.932

Aguilar-Gaxiola, S. A., Zelezny, L., Garcia, B., Edmondson, C., Alejo-Garcia, C., \& Vega, W. A. (2002). Translating research into action: Reducing disparities in mental health care for Mexican Americans. Psychiatric Services, 53(12), 1563-1568.

Abraido-Lanza, A. F., Armbrister, A., Florez, K. R., \& Aguirre, A. N. (2006). Toward a theory-driven model of acculturation in public health research. American Journal of Public Health, 96(8), 1342-1346. doi:10.2105/AJPH.2005.064980 
Belkin-Martinez, D. (2010). Solidaridad y justicia: Latinas, community organizing, and empowerment. In R. Furman \& N. Negi (Eds.), Social work practice with Latinos: Key issues and emerging themes (pp. 282-291). Chicago, IL: Lyceum Books.

Bent-Goodley, T. B. (2005). Culture and domestic violence: Transforming knowledge development. Journal of Interpersonal Violence, 20(2), 195-203. doi:10.1177/0886260504269050

Bernal, G., Bonilla, J., \& Bellido, C. (1995). Ecological validity and cultural sensitivity for outcome research: Issues for the cultural adaptation and development of psychosocial treatments with Hispanics. Journal of Abnormal Child Psychology, 23(1), 67-82. doi:10.1007/BF01447045

Bronfenbrenner, U. (1979). The ecology of human development: Experiments by nature and by design. Cambridge, MA: Harvard University Press.

Cabassa, L. J. (2003). Measuring acculturation: Where we are and where we need to go. Hispanic Journal of Behavioral Sciences, 25(2), 127-146. doi:10.1177/0739986303025002001

Castillo-Mancilla, J., Allshouse, A., Collins, C., Hastings-Tolsma, M., Campbell, T.B., \& Mawhinney, S. (2012) Differences in sexual risk behavior and HIV/AIDS risk factors among foreign-born and US-born Hispanic women. Journal of Immigrant and Minority Health, 14(1), p. 89-99. doi:10.1007/s10903-011-9529-7

Centers for Disease Control and Prevention. (2012). CDC fact sheet: HIV and AIDS among Latinos. USDHHS. Retrieved from http://www.cdc.gov/nchhstp/newsroom/docs/2012/CDC-Latinos/Latinas-1012508.pdf

Chang-Muy, F., \& Congress, E. (Eds.). (2009). Social work with immigrants and refugees: Legal issues, clinical skills, and advocacy. New York, NY: Springer.

Chavez, L. R. (2004). A glass half empty: Latina reproduction and public discourse. Human Organization, 63(2), 173-189.

Chun, K. M., Organista, P. B., \& Marín, G. (Eds.). (2002). Acculturation: Advances in theory, measurement, and applied research. Washington, DC: American Psychological Association.

Cohen, S. J., Meister, J. S., \& deZapien, J. G. (2004). Special action groups for policy change \& infrastructure support to foster healthier communities on the ArizonaMexico border. Public Health Reports, 119(1), 40-47. doi:10.1016/j.phr.2004.03.010

Congress, E. (2006). Teaching social work values, ethics, and human rights. Social work around the world (Vol. IV). Berne, Switzerland: IFSW.

Council on Social Work Education. (2012). Educational policy and accreditation standards. Retrieved from http://www.cswe.org/File.aspx?id=13780

Cravey, A., \& Valdivia, G. (2011) Carolina del Norte: An introduction. Southeastern Geographer, 51(2), 213-226. doi:10.1353/sgo.2011.0019 
Cuadros, P. (2011). We play too: Latina integration through soccer in the "New South." Southeastern Geographer, 51(2), 227-241. doi:10.1353/sgo.2011.0021

DeRose, K. P., Escarce, J. J., \& Lurie, N. (2007). Immigrants and health care: Sources of vulnerability. Health Affairs, 26(5), 1258-1268. doi:10.1377/hlthaff.26.5.1258

Deguzman, M. (2011). The emerging geographies of a Latina/o studies program. Southeastern Geographer, 51(2), 307-326. doi:10.1353/sgo.2011.0017

Delgado, M. (2007). Social work with Latinos: A cultural assets paradigm. New York, NY: Oxford University Press.

Delgado, M. (2012). Latino small businesses and the American dream: Community social work practice and economic and social development. New York, NY: Columbia University Press.

Fraser, M. W. (2004). The ecology of childhood: A multisystems perspective. In M. Fraser (Ed.), Risk and resilience in childhood: An ecological perspective $\left(2^{\text {nd }}\right.$ ed., pp. 1-12). Washington, DC: NASW Press.

Friedman, S. R., Curtis, R., Neaigus, A., Jose, B., \& Des Jarlis, D.C. (1999). Social networks, drug injectors' lives, and HIV/AIDS. New York, NY: Kluwer Academic/Plenum.

Furman, R., Negi, N. J., \& Loya, M. (2010). Introduction. In R. Furman \& N. Negi (Eds.), Social work practice with Latinos: Key issues and emerging themes (pp. $\mathrm{x}-12$ ). Chicago, IL: Lyceum Books.

Furuseth, O. J., \& Smith, H. A. (Eds.). (2006). Latinos in the New South. Surrey, England: Ashgate.

Garcia, A. (2009). Contextual pathways to Latino child welfare involvement: A theoretical model located in the intersections of place, culture, and socio-structural factors. Children \& Youth Service Review, 31(12), 1240-1250. doi:10.1016/j.childyouth.2009.05.009

Gill, H. (2012). Latinos in North Carolina: A growing part of the state's economic and social landscape. Retrieved from http://immigrationpolicy.org/perspectives/latinosnorth-carolina-growing-part-states-economic-and-social-landscape

Gill, H., Nguyen, M., Parker, K., \& Weissman, D. (2009). Legal and social perspectives on local enforcement of immigration under the Section 287(g) program. Popular Government, 74(3), 2-21.

Galarneau, C. (2011). Still Missing: Undocumented immigrants in health care reform. Journal of Health Care for the Poor and Underserved, 22(2), 422-428. doi:10.1353/hpu.2011.0040

Gutiérrez, L. M., \& Lewis, E. A. (1999). Empowering women of color. New York, NY: Columbia University Press. 
Hacker, K., Chu, J., Arsenault, L., \& Marlin, R. P. (2012). Providers' perspectives on the impact of immigrations and customs enforcement (ICE) activity on immigrant health. Journal of Healthcare for the Poor and Underserved, 23(2), 651-665. doi:10.1353/hpu.2012.0052

Hernández, D. M. (2008). Pursuant to deportation: Latinos and immigrant detention. Latino Studies, 6, 35-63. doi:10.1057/lst.2008.2

Hunt, L. M., Schneider, S., \& Comer, B. (2004). Should "acculturation" be a variable in health research? A critical review of research on US Hispanics. Social Science \& Medicine 59(5), 973-986. doi:10.1016/j.socscimed.2003.12.009

Idilbi, J. G. (2008). Local enforcement of federal immigration law: Should North Carolina communities implement 287(g) authority? North Carolina Law Review, 86, 1711-1742.

Iglehart, A. P., \& Becerra, R. M. (1995/2000). Social services and the ethnic community. Prospect Heights, IL: Waveland Press.

Ingram, M., Gallegos, G., \& Elenes, J. (2005). Diabetes is a community issue: The critical elements of a successful outreach \& education model on the U.S.-Mexico border. Preventing Chronic Disease, 2(1). Retrieved from http://www.cdc.gov/pcd/issues/2005/jan/04 0078.htm

Johnson-Webb, K. (2003). Recruiting Hispanic labor: Immigrants in non-traditional areas. New York, NY: LFB Scholarly.

Katz, M. (1996). In the shadow of the poorhouse: A social history of welfare in America ( $2^{\text {nd }}$ ed.). New York, NY: Basic Books.

Love, M. B., Gardner, K., \& Legion, V. (1997). Community health workers: Who they are and what they do. Health Education \& Behavior, 24(4), 510-522.

Martinez, H., \& Bazan, A. (2004) Health disparities among North Carolina's Latinos. North Carolina Medical Journal, 65(6), 356-358.

McLeigh, J. D. (2010). How do immigration and customs enforcement (ICE) practices affect the mental health of children? American Journal of Orthopsychiatry, 80(1), 96100. doi:10.1111/j.1939-0025.2010.01011.x

Molina, N. (2006a). Medicalizing the Mexican: Immigration, race, and disability in the early-twentieth-century United States. Radical History Review, 94, 22-37.

Molina, N. (2006b) Fit to be citizens?: Public health and race in Los Angeles, 1879-1939. Los Angeles: University of California Press.

Nash, M., Wong, J., \& Trilin, A. (2006). Civic and social integration: A new field of social work practice with immigrants, refugees and asylum seekers. International Social Work, 49(3), 345-363. 
National Association of Social Workers (NASW). (2008). Code of ethics: Section 1.05 Cultural competence and social diversity. Retrieved from http://www.socialworkers.org/pubs/code/code.asp

NASW. (2012). Immigration and refugee resettlement. Retrieved from http://www.socialworkers.org/practice/intl/issues/immigration.asp

Negi, N. J., \& Furman, R. (Eds.). (2010). Transnational social work practice. New York, NY: Columbia University Press.

Nemcek, M. A., \& Sabatier, R. (2003). State of evaluation: community health workers. Public Health Nursing, 20(4), 260-270. doi:10.1046/j.1525-1446.2003.20403.x

Nguyen, M. T., \& Gill, H. E. (2010). The 287(g) program: The costs and consequences of local immigration enforcement in North Carolina communities. Chapel Hill, NC: University of North Carolina. Retrieved from http://cgi.unc.edu/uploads/media_items/287g-report-final.original.pdf

North Carolina Office of Minority Health \& Health Disparities and the State Center for Health Statistics. (2010). Racial and Ethnic Health Disparities in North Carolina: Report Card 2010. Retrieved from http://www.schs.state.nc.us/SCHS/pdf/MinRptCard WEB 062210.pdf

Ojeda, V. D., Burgos, J. L., Hiller, S. P., Lozada, R., Rangel, G., Vera, A., ... MagisRodriguez, C. (2012). Circular migration by Mexican female sex workers who are injection drug users: Implications for HIV in Mexican sending communities. Journal of Immigrant Minor Health, 14(1), 107-115.

Painter, T. M. (2008). Connecting the dots: When the risks of HIV/STD infection appear high but the burden of infection is not known-The case of male Latino migrants in the southern United States. AIDS and Behavior, 12(2), 213-226. doi: 10.1007/s10461-007-9220-0

Palis, J., Reilly, M., \& Valdivia, G. (2011) Borders, border-crossing, and political art in North Carolina. Southeastern Geographer, 51(2), 287-306.

Pew Hispanic Center. (2011). Census 2010: 50 Million Latinos: Hispanics account for more than half of nation's growth in past decade. Retrieved from http://www.pewhispanic.org/files/reports/140.pdf

Popke J. (2011). Latino migration and neoliberalism in the U.S. South: Notes toward a rural cosmopolitanism. Southeastern Geographer, 51(2), 242-259.

Portes, A., \& Rumbaut, R. G. (2006) Immigrant America: A portrait. Berkeley: University of California Press.

Ramos, I. N., May, M., \& Ramos, K. S. (2001). Environmental health training of Promotoras in Colonias along the Texas-Mexico border. American Journal of Public Health, 91(4), 568-570.

Redfield, R., Linton, R., \& Herskovits, J. J. (1936). A memorandum for the study of acculturation. American Anthropologist, 38(1), 149-152. 
Ro, M. J., Treadwell, H. M., \& Northridge, M. (2003) Community health workers and community voices: Promoting good health. A Community Voices Publication Retrieved from http://www.communityvoices.org/Libraries/Community_Voices_Documents/resourc eLibrary_communityHealthWorkers_promotingGoodHealth.sflb.ashx

Roosa, M. R., Weaver, S. R., White, R. M. B., Tein, J. Y., Knight, G. P., Gonzales, N., \& Saenz, D. (2009). Family and neighborhood fit or misfit and the adaptation of Mexican Americans. American Journal of Community Psychology, 44(1-2), 15-27.

Saleebey, D. (Ed.) (2002). The strengths perspective in social work practice (2nd ed.) New York, NY: Allyn \& Bacon.

Siman, F. (2009) Cross-cultural issues and health care advocacy for immigrants in North Carolina. North Carolina Medical Journal, 70(2), 149-152.

Simmons, A. B. (Ed). (1996). International migration, refugee flows, and human rights in North America: The impact of free trade and restructuring. New York, NY: Center for Migration Studies Press.

Smokowski, P. R., \& Bacallao, M. (2011). Becoming bicultural: Risk, resilience, and Latino youth. New York, NY: New York University Press.

Tazreiter, C. (2006). Between state sovereignty and invisibility: Monitoring the human rights of returned asylum seekers. Australian Journal of Human Rights, 11(2), 7-25.

Tervalon, M., \& Murray-Garcia, J. (1998). Cultural humility versus cultural competence: A critical distinction in defining physician training outcomes in multicultural education. Journal of Health Care for the Poor and Underserved, 9(2), 117-125.

Thomson, M., \& Hoffman-Goetz, L. (2009). Defining and measuring acculturation: A systematic review of public health studies with Hispanic populations in the USA. Social Science and Medicine, 69(7), 983-991.

Touzenis, K., \& Cholewinski, R. (2009). The human rights of migrants- Editorial introduction. International Journal on Multicultural Societies, 11(1), 1-18.

U.S. Census Bureau. (2005-2009). American Community Survey 5 Year Estimates. Retrieved from http://factfinder.census.gov/servlet/DatasetMainPageServlet?_program=ACS\& subm enuId $=\&$ lang $=$ en $\&$ ts $=$

U. S. Census Bureau. (2010). 2010 Census: State population profile maps. Retrieved from http://2010.census.gov/2010census/

Vega, W. A., \& Amaro, H. (2002). Latino outlook: Good health, uncertain prognosis. In T. A. LaVeist (Ed.), Race, ethnicity, and health-A public health reader (pp. 47-75). San Francisco, CA: Jossey-Bass.

Vega, M., \& Cherfas, L. (2012). The landscape of Latina HIV prevention interventions and their implementation. In K. C. Organista (Ed.), HIV Prevention with Latinos: 
Theory, research, and practice (pp. 329-350). New York, NY: Oxford University Press.

Wallace, M. P., Pomery, E. A., Latimer, A. E., Martinez J. L., \& Salovey, P. (2012). A review of acculturation measures and their utility in studies promoting Latino health. Hispanic Journal of Behavioral Sciences, 32(1), 37-54.

Warner, L. A., Valdez, A., Vega, W.A., de la Rosa, M., Turner, J. R., \& Canino, G. (2006). Hispanic drug abuse in an evolving cultural context: An agenda for research. Drug and Alcohol Dependence, 84(Suppl.), 8-16.

Weil, M., Reisch, M., \& Ohmer, M. (Eds.). (2012). The handbook of community practice $\left(2^{\text {nd }}\right.$ ed.). Thousand Oaks, CA: Sage.

Weissman, D. (2009). The policies and politics of local immigration enforcement laws: 287(g) program in North Carolina. Chapel Hill, NC: University of North Carolina. Retrieved from http://www.law.unc.edu/documents/clinicalprograms/287gpolicyreview.pdf

Witmer, A., Seifer, S. D., Finocchio, L., Leslie, J., \& O'Neil, E. H. (1995). Community health workers: Integral members of the health care work force. American Journal of Public Health, 85(8 Pt.1), 1055-1058.

Yamada, A. M., Valle, R., Barrio, C., \& Jeste, D. (2006). Selecting an acculturation measure for use with Latino older adults. Research on Aging, 28(5), 519-561.

Zerden, L. D., López, L. M., \& Lundgren, L. (2010). Needle sharing among Puerto Rican injection drug users in Puerto Rico and Massachusetts: Place of birth and residence matter. Substance Use and Misuse, 45(10), 1605-1622.

Zambrana, R. E., \& Carter-Pokras, O. (2010). Role of acculturation research in advancing science and practice in reducing health care disparities among Latinos. American Journal of Public Health, 100(1), 18-23.

Zota, S. (2008). Immigrants in North Carolina: A fact sheet. Popular Government. (Fall) 38-44. Retrieved from http://sogpubs.unc.edu/electronicversions/pg/pgfal08/article4.pdf

\section{Author note:}

Direct correspondence to: Lisa de Saxe Zerden, MSW, PhD, Clinical Assistant Professor, UNC Chapel Hill School of Social Work, 325 Pittsboro St. CB\#3550, Chapel Hill, NC 27599-3550. Email: Lzerden@email.unc.edu 